\title{
Acute changes in oxygen consumption and body temperature after burn injury
}

\author{
Charmaine Childs, R A Little
}

\begin{abstract}
This study describes the pattern of oxygen consumption $\left(\dot{\mathbf{V}} \mathrm{O}_{2}\right)$, rectal temperature $\left(T_{r}\right)$, and acral skin temperature $\left(T_{a c}\right)$ in sleeping and resting (awake) burned children nursed in a thermoneutral environment. Measurements of respiratory gas exchange $\left(\dot{\mathrm{V}} \mathrm{O}_{2}\right.$ and carbon dioxide production $\left(\dot{\mathrm{V}} \mathrm{CO}_{2}\right)$ ) were made using an open circuit, flow through system of indirect calorimetry. $T_{r}$ and $T_{a c}$ were monitored continuously. Sixteen patients were studied during the first 18 hours after being burned.

Three phases of change in $\dot{V} o_{2}, T_{r}$, and $T_{\text {ac }}$ are described. The first was a stable period and there was little change from admission values. The second (7-10 hours after burn) was a phase of rapid heat storage. It started with a fall in $T_{\text {ac }}$. Peak values of $T_{r}\left(38 \cdot 8-41 \cdot 1\right.$, median $\left.40.0^{\circ} \mathrm{C}\right)$ and $\dot{V} \mathrm{O}_{2}(8 \cdot 5-11 \cdot 8 \mathrm{ml} / \mathrm{min} / \mathrm{kg})$ occurred either in phase 2 or in the later phase 3. At its peak $\dot{V} \mathrm{O}_{2}$ was $12-61 \%$ above values in phase 1 . In phase $3, T_{a c}$ returned towards admission values but $T_{r}$ and $\dot{V} o_{2}$ were variable. These changes suggest that both an increase in metabolic heat production as well as heat conservation at the extremities may be involved in the generation of early fever after a burn.
\end{abstract}

(Arch Dis Child 1994; 71: 31-34)

Fever is a characteristic feature of the acute response to moderate and severe burn injury in infants and young children. Six to eight hours after the accident, deep body temperature rises rapidly and skin temperature in acral regions falls. ${ }^{1}$ These changes reflect the onset of a disturbance in thermoregulation that persists for at least the first 24-48 hours after the event. This pattern of change in body temperature appears to be confined to burned children. While a rise in deep body temperature has been shown in burned adults, the peak is not reached until about 24 hours after the burn. ${ }^{2}$ The increased amount of heat stored acutely in these children fails to stimulate efferent pathways of heat loss. Sweating is inhibited and heat loss is reduced in acral regions. Despite differences in the routes for heat loss by radiation, convection and evaporation, total heat loss is not very different from that of healthy apyrexial children exposed to similar environmental conditions. ${ }^{3}$ The rise in deep body temperature must therefore involve an increase in oxygen consumption and metabolic heat production. ${ }^{3}$ In this study, oxygen consumption has been measured by indirect calorimetry in a group of burned children nursed in a thermoneutral environment during the first 18 hours after the event. The results were compared with those in healthy children studied under similar environmental conditions. ${ }^{4}$

\section{Methods}

We studied patients with burns of $10 \%$ or more of the body surface, admitted to the regional children's Burns Unit. These children were transferred by ambulance to the unit as emergency cases, either directly from their homes or from accident and emergency departments of district hospitals within the North Western region.

On arrival, the patients were weighed and height was measured. They were admitted into an intensive care room maintained at an ambient temperature of approximately $30^{\circ} \mathrm{C}$. They were resuscitated with intravenous colloid (fresh frozen plasma) and crystalloid $(0.45 \%$ sodium chloride in $5 \%$ dextrose), for approximately 36 hours, guided by the Mount Vernon formula. ${ }^{5}$ All patients were given intravenous morphine sulphate $(0.2 \mathrm{mg} / \mathrm{kg})$ every 4-6 hours for analgesia. Patients were sedated with oral trimeprazine tartrate (Vallergan, Rhône Poulenc Rorer), 2-3 mg/kg when necessary. Clear fluids only were given by mouth (or via a nasogastric tube) during the resuscitation period. All burns were cleaned with $0.9 \%$ sodium chloride and covered by wet soaks of povidone iodine (Betadine, Beecham Research Laboratories) or $0.9 \%$ sodium chloride. The dressings were then covered with sterile dry gauze and wrapped with crepe bandages, secured with tape.

On occasions, oral administration of paracetamol was given during the study period.

\section{EQUIPMENT}

\section{Temperature monitoring}

Rectal temperature $\left(T_{r}\right)$ was measured with a thermistor inserted, on admission, into the rectum, 4-6 cm from the anus ${ }^{6}$; temperature was recorded throughout the resuscitation period. A continuous display was produced by a battery operated monitor (Libra Medical). Surface temperature in acral regions $\left(T_{a c}\right)$ was measured with a thermistor, attached to the pulp of the thumb or hallux with Mefix tape (Molnlycke). Ambient temperature was 
Table 1 Details of patients

\begin{tabular}{llllccl}
\hline $\begin{array}{l}\text { Patient } \\
\text { No }\end{array}$ & $\begin{array}{l}\text { Age } \\
\text { (years) }\end{array}$ & $\begin{array}{l}\text { \%Burn } \\
\text { TBSA }\end{array}$ & Injury & $\begin{array}{l}\text { Weight } \\
(\mathrm{kg})\end{array}$ & $\begin{array}{c}\text { Height } \\
(\mathrm{cm})\end{array}$ & $\begin{array}{l}\text { Surface } \\
\text { area }\left(\mathrm{m}^{2}\right)\end{array}$ \\
\hline 1 & 1.9 & 25 & Scald & 12.5 & 86 & 0.55 \\
2 & 1.0 & 18 & Scald & 9.1 & 72 & 0.43 \\
3 & $8 \cdot 8$ & 55 & Burn & 25.0 & 131 & 0.95 \\
4 & 3.9 & 21 & Burn & 17.0 & 103 & 0.69 \\
5 & 1.1 & 12 & Scald & 9.0 & 79 & 0.45 \\
6 & 1.9 & 28 & Scald & 13.5 & 88 & 0.58 \\
7 & 2.9 & 30 & Scald & 15.0 & 89 & 0.62 \\
8 & 3.3 & 10 & Scald & 15.5 & 98 & 0.65 \\
9 & 1.9 & 22 & Scald & 13.5 & 90 & 0.58 \\
10 & 0.9 & 10 & Scald & 12.0 & 76 & 0.51 \\
11 & $5 \cdot 7$ & 21 & Scald & 16.0 & 102 & 0.67 \\
12 & 1.4 & 23 & Scald & 12.5 & 82 & 0.54 \\
13 & 1.1 & 11 & Scald & 9.0 & 72 & 0.43 \\
14 & 1.6 & 12 & Scald & 10.0 & 78 & 0.47 \\
15 & 1.3 & 16 & Scald & 12.0 & 84 & 0.53 \\
16 & 0.8 & 20 & Scald & 7.6 & 70 & 0.39 \\
\hline
\end{tabular}

$\star$ TBSA=total body surface area.

measured using an 'Edale Weather Station' (Edale Instruments).

\section{Indirect calorimetry}

A specially designed open circuit flow through system of indirect calorimetry was used for the measurement of oxygen consumption $\left(\mathrm{V}_{2}\right)$ and carbon dioxide production $\left(\dot{\mathrm{V}} \mathrm{CO}_{2}\right)$. A detailed description of the design, construction, and validation of this system has been previously reported. ${ }^{7}$ The indirect calorimetry system was set up in the intensive care room before the patient arrived at the burns unit, so that measurements could begin with minimum delay. The child's exhaled breath was collected into a facemask which was designed for use in infants and small children. ${ }^{7}$ The mask was held gently over the nose and mouth. It was designed to give a good seal around the face to prevent leakage of the child's expired air from the mask but also allowed an adequate flow of air to the child. Ambient air, drawn into the mask via two open Silastic 'horns' on the upper body of the mask, mixes with the child's expired respiratory gas and this gas mixture was drawn from the mask to gas analysers at a flow rate within the range 20-30 1/min.
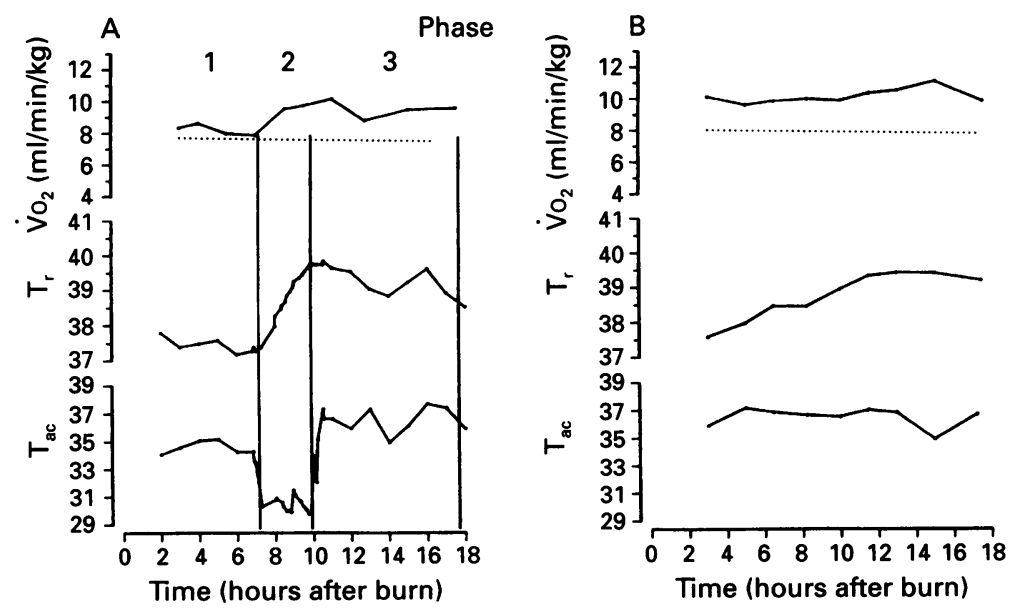

(A) $V_{\mathrm{O}_{2}}, T_{r}$ and $T_{a c}$ (toe) in a patient in each of three phases. This pattern forms the more typical changes seen in the first 18 hours after burn injury in the patients studied. (B) $\mathrm{VO}_{2}, T_{r}$ and $T_{a c}$ in one of two patients who did not show the typical pattern.

\section{MEASUREMENTS}

\section{Patients}

Measurements were started as soon as possible after the child was admitted to the burns unit. Sometimes this was within the first hour after admission, when there was a convenient break in treatment, and usually before cleaning, debridement, and dressing of the wound. This first measurement was followed by a series of measurements made once the bandages had been applied. Whenever possible, measurements were made every 1-2 hours during the first 18 hours after the burn when the children were awake (resting) and during sleep.

\section{Controls}

Measurements of respiratory gas exchange in the patients were compared with measurements made in a group of healthy children described previously. ${ }^{4}$ The healthy subjects had been studied under similar conditions as the patients in this study - that is, asleep or awake (resting) in a thermoneutral environment and with insulation approximating to a lightly clothed subject.

\section{STATISTICS}

Results are expressed as median and range or, where appropriate, as mean (SD).

\section{ETHICS}

This study was approved by the North Manchester district ethics committee.

\section{Results}

We studied 16 patients aged $0 \cdot 8-8 \cdot 8$ years (median 1.7 years) with a mixture of partial and full thickness burns covering $10-55 \%$ (median $20.5 \%$ ) of the body surface (table 1 ). The children were studied in ambient temperatures of $30.5(0.95)^{\circ} \mathrm{C}$.

In 10 patients the changes in $T_{r}, T_{a c}$, and $\dot{\mathrm{V}} \mathrm{O}_{2}$ formed a typical pattern during the first 18 hours which could be divided into three phases (fig A) and this has helped describe the relation between the parameters measured. In six patients there was incomplete measurement of one or more parameters at some time during the study so the overall pattern of changes in these patients are not described. In two patients the pattern was atypical (fig B).

While there was a similar pattern to the changes in $T_{r}, T_{a c}$, and $\dot{V}_{2}$ in the 10 patients, the timing of the onset of changes differed by an hour or so between patients. The phases described below represent the events and timing of the changes taking place. In most cases the pattern of changes in body temperature was not influenced by antipyretic drugs. Four patients only received paracetamol during the period relevant to this study.

\section{PHASE 1}

Phase 1 was characterised by a stable $T_{r}, T_{a c}$, and $\dot{\mathrm{V}} \mathrm{O}_{2}$ (figure) and all patients showed these 
Table $2 \quad \dot{V}_{2}$ on admission

\begin{tabular}{llccl}
\hline $\begin{array}{l}\text { Patient } \\
\text { No }\end{array}$ & $\begin{array}{l}\text { Sleeping/ } \\
\text { awake }\end{array}$ & $\begin{array}{l}\text { Measured } \\
\dot{V} \mathrm{O}_{2} \\
(\mathrm{~mL} / \mathrm{min} / \mathrm{kg})\end{array}$ & $\begin{array}{l}\text { Normal } \\
\text { range } \dot{V} \mathrm{O}_{2} \dagger \\
(\mathrm{mL} / \mathrm{min} / \mathrm{kg})\end{array}$ & $\begin{array}{l}\text { Hours } \\
\text { after } \\
\text { burn }\end{array}$ \\
\hline 1 & Sleeping & $9 \cdot 0$ & $6 \cdot 3-9 \cdot 0$ & $6 \cdot 0$ \\
2 & Awake & $11 \cdot 9$ & $10 \cdot 6-14 \cdot 9$ & $3 \cdot 5$ \\
3 & Awake & $6 \cdot 6$ & $3 \cdot 8-8 \cdot 1$ & $5 \cdot 0$ \\
4 & Sleeping & $7 \cdot 4$ & $5 \cdot 5-8 \cdot 3$ & $3 \cdot 0$ \\
5 & Sleeping & $8 \cdot 3$ & $6 \cdot 6-9 \cdot 4$ & $3 \cdot 5$ \\
6 & Awake & $10 \cdot 4$ & $9 \cdot 3-13 \cdot 6$ & $3 \cdot 5$ \\
7 & Sleeping & $8 \cdot 3$ & $6 \cdot 0-8 \cdot 7$ & $3 \cdot 8$ \\
8 & Sleeping & $7 \cdot 6$ & $5 \cdot 8-8 \cdot 5$ & $4 \cdot 5$ \\
9 & Sleeping & $9 \cdot 4$ & $6 \cdot 3-9 \cdot 0$ & $3 \cdot 8$ \\
10 & Awake & $7 \cdot 4$ & $10 \cdot 6-15 \cdot 0$ & $6 \cdot 0$ \\
11 & Awake & $8 \cdot 8$ & $5 \cdot 5-9 \cdot 7$ & $6 \cdot 0$ \\
12 & Awake & $8 \cdot 8$ & $10 \cdot 0-14 \cdot 3$ & $5 \cdot 5$ \\
13 & Sleeping & $8 \cdot 3$ & $6 \cdot 6-9 \cdot 4$ & $5 \cdot 0$ \\
14 & Sleeping & $8 \cdot 2$ & $6 \cdot 4-9 \cdot 1$ & $3 \cdot 0$ \\
15 & Sleeping & $8 \cdot 4$ & $6 \cdot 5-9 \cdot 2$ & $3 \cdot 0$ \\
16 & Sleeping & $10 \cdot 2$ & $6 \cdot 7-9 \cdot 5$ & $3 \cdot 0$ \\
& & & &
\end{tabular}

*Awake at time of measurement.

†Normal range of $\mathrm{VO}_{2}$ constructed from upper and lower $95 \%$ confidence intervals of healthy children of same age and same conditions (that is, awake or asleep) ${ }^{4}$

features during the first few hours after the accident. Measurements of $T_{r}$ were started within six hours of the burn at about the time of the first measurement of $\dot{\mathrm{V}} \mathrm{O}_{2}$. Mean (SD) admission $T_{r}$ was $37.6(0.50)^{\circ} \mathrm{C}(n=16)$ and $\mathrm{T}_{\mathrm{ac}} 35.6(0.84)^{\circ} \mathrm{C}(\mathrm{n}=15)$. The temperature gradient between $T_{r}$ and $T_{a c}$ was $1 \cdot 0-3 \cdot 6^{\circ} \mathrm{C}$ (median $1.85^{\circ} \mathrm{C}$ ).

The first measurement of $\dot{\mathrm{V}} \mathrm{O}_{2}$ was made 3-6 hours (median 3.75 hours) after the burn and values at this time were compared with measurements made in healthy children of the same age (table 2). As some patients $(n=6)$ were awake and resting and others $(n=10)$ were sleeping at the time the measurements of $\dot{V}_{2}$ were made, it was important to make the comparison with correct control values (table 2). Only two patients, numbers 9 and 16, had a $\dot{\mathrm{V}}_{2}$ above the normal range $(95 \%$ confidence interval) for an appropriate control subject.

Where complete data were available $(n=15)$ during phase $1, T_{r}$ and $T_{a c}$ were stable. $T_{r}$ changed by only $0.42(0.3)^{\circ} \mathrm{C}$ around the admission value (that is, above or below it). Phase 1 ended when $T_{a c}$ started to fall (fig A).

PHASE 2

The changes in the relationship between $T_{r}$, $\mathrm{T}_{\mathrm{ac}}$, and $\dot{\mathrm{VO}}_{2}$ described in phase two and three refer to data from the 10 patients in whom complete data are available during the whole 18 hour period as described above.

Phase 2 started with a fall in $T_{a c}$ and ended when it reached a nadir (fig $A$ ). The fall in $T_{a c}$ was seen in all 10 patients and was followed by increases in $T_{r}$ and $\dot{V}_{2}$. The nadir in $T_{a c}$ was reached 9-12 hours (median 9.75 hours) after the accident with a maximum fall of $3 \cdot 4^{\circ}-5 \cdot 5^{\circ} \mathrm{C}$ (median $4 \cdot 75^{\circ} \mathrm{C}$ ). At this time, $\mathrm{T}_{\mathrm{r}}$ reached $38.3^{\circ}-41.1^{\circ} \mathrm{C}$ (median $39.5^{\circ} \mathrm{C}$ ) and $\dot{\mathrm{V}}_{2}$ was $4-36 \%$ (median $24 \%$ ) above the admission values (measured in phase 1 ) in nine patients and values ranged from 8.3-11.5 (median $10.1 \mathrm{ml} / \mathrm{min} / \mathrm{kg}$ ). This represented an increase above the control range for eight patients. (In the two remaining patients $\mathrm{VO}_{2}$ fell slightly in one and remained the same in the other patient.)
PHASE 3

This phase was characterised by a rise in $T_{a c}$ to values close to or slightly above those recorded in phase 1 immediately after the injury (fig A). Maximum values for $\mathrm{VO}_{2}$ in the 10 patients described above had either been reached during phase $2(n=6)$, or were delayed until phase $3(n=4)$. At its peak (either in phase 2 or 3), $\dot{\mathrm{V}} \mathrm{O}_{2}$ was variable and ranged from $12-61 \%$ (median 29\%) above that measured during phase 1.

The peak increase in $T_{r}\left(38.8-41 \cdot 1^{\circ} \mathrm{C}\right.$, median $40.0^{\circ} \mathrm{C}$ ) usually occurred during the same phase as the peak in $\dot{\mathrm{V}} \mathrm{O}_{2}(8 \cdot 5-11 \cdot 78$, median $10.35 \mathrm{ml} / \mathrm{min} / \mathrm{kg}$ ), that is, in $8 / 10$ cases. In the remaining two patients, $\dot{\mathrm{V}}_{2}$ reached a peak before the peak increase in $\mathrm{T}_{\mathrm{r}}$.

\section{Discussion}

The pattern of change in deep body temperature recorded acutely after burn injury in children nursed in a thermoneutral environment confirms that reported previously. ${ }^{18}$

The failure of the acute increases in $T_{r}$ and heat content to elicit compensatory increases in heat loss has been interpreted as evidence for a change in thermoregulatory control in such children. ${ }^{9}$ Indeed, an inhibition of sweating in unburned skin and a reduction in acral temperature were noted at this time. ${ }^{3}$ In the present study, the harbinger of a change in thermal homoeostasis was a rapid fall in acral temperature (mean $31^{\circ} \mathrm{C}$ ) to a value close to ambient temperature $\left(30^{\circ} \mathrm{C}\right)$. The change in acral temperature could not be attributed to any cardiovascular change as reflected by heart rate, blood pressure, or fluid administration.

The dramatic fall in acral temperature was followed by increases in rectal temperature and oxygen consumption. Measurements of $\dot{\mathrm{VO}}_{2}$ have not been observed previously in acutely burned children. The problems inherent in many commercial systems were overcome by the development of a purpose built open circuit, flow through system. ${ }^{7}$ This system enables respiratory gas exchange to be measured with minimal disturbance to sleeping or awake children. ${ }^{4}$ A limitation of this system, in non-steady state conditions, is that the calculations of $\dot{\mathrm{VO}}_{2}$ are made from respiratory gas exchange measurements integrated over approximately 15 minutes. Thus it is difficult to discern from the present data whether the increase in $\dot{\mathrm{V}}_{2}$ occurred before the rise in core temperature which, in the burned children, was measured continuously. It has been shown previously that a rise in $\dot{\mathrm{V}}_{2}$ precedes the development of fever in volunteers given typhoid vaccine. ${ }^{10}$ Preliminary results obtained recently by our group, using minute to minute measurements of $\dot{\mathrm{V}}_{2}$ in burned children, suggest that $\mathrm{V}_{2}$ does indeed rise before $T_{r}{ }^{11}$

The maximal rises in $\dot{\mathrm{V}}_{2}$ (median $29 \%$ ) noted in either phase 2 or 3 were less than predicted from a $Q_{10}$ value of $2 \cdot 3 .^{12}$ Although this value is widely quoted in reference to the rate of biological processes in homoeotherms, it is possible that under certain conditions in 
man the value may be more variable ( $M$ Ducharme; personal communication). Also, the increases in $\dot{\mathrm{VO}}_{2}$ were too large to be explained by a change in substrate oxidation. A change from carbohydrate to fat oxidation, which is a feature of the response to injury, ${ }^{13}$ means that in order to maintain a set level of heat production, more oxygen (at most 7\%) must be consumed. Thus it seems that during the acute phase of the response to burn injury in children, an increase in heat production and a reduction in heat loss both contribute to the increase in core temperature.

The changes in core temperature, $T_{a c}$, and $\dot{\mathrm{V}} \mathrm{O}_{2}$ can be explained by an upward resetting of thermoregulation initiated by injury. Although such a change is a characteristic of the later 'flow' or hypermetabolic response to burn injury, it is not generally recognised as part of the acute phase response (APR) in man. However, the term APR is now used to describe all events which, although initiated at the time of injury, may take some time to be fully expressed. This acute change in thermoregulatory control is unlikely to be due to secondary infection of the burn wound but inflammatory cells activated within the wound may be involved. Cytokines such as interleukin-1 (IL-1) and interleukin-6 (IL-6) have been detected in blister fluid of burned children soon after injury and plasma concentrations of IL- 6 are also raised at this time. ${ }^{14}$ Inflammatory cytokines may also be liberated from organs such as the liver after an increase in bacterial translocation from the gut, ${ }^{15}$ the permeability of which is increased acutely after burn injury in children. ${ }^{16}$ The central mediation of cytokine induced fever involves at least corticotrophin releasing factor and the prostaglandins. ${ }^{17}$ In the present study, abolition of the early rise in deep body (rectal) temperature in the burned child by the cyclo-oxygenase inhibitor, paracetamol, offers support for the role of prostaglandins. ${ }^{18}$ In summary, the development of fever in acutely burned children is accompanied, in most cases, by increases in oxygen consumption. It is still not clear whether this increase is a cause of the fever or whether it is secondary to it. The relative contributions of heat loss and heat production to the development of fever may depend on environmental temperature. For example, it has been shown in rabbits that peripheral vasoconstriction (leading to reduced heat loss) is most important in the warm $\left(24^{\circ} \mathrm{C}\right)$, whereas in the cold $\left(10^{\circ} \mathrm{C}\right)$ heat production is predominant. ${ }^{19}$ Irrespective of the mechanism of the increase in rectal temperature, it is clear that its achievement is associated with an 'energy cost', the magnitude of which may be influenced by ambient temperature. It is important to be aware of such a change and the effects it has on energy balance, as failure to adequately feed burned children may compromise recovery and subsequent growth. ${ }^{20}$

We would like to thank Professor H B Stoner for his advice during this study and Mr Peter J Davenport FRCS and Mr John Lendrum FRCS for allowing study of the patients in their care. Many thanks to the nurses and doctors of the burns unit for their continued help and support. This study was funded by the Sir Jules Thorn Charitable Trust.

1 Childs C. Fever in burned children. Burns 1988; 14: 1-6. 2 Martineau L, Little RA, Campbell IT, Davenport PJ, Rothwell NJ. Changes in core temperature in the early post burn period in adults. Circ Shock 1991; 34: 10.

3 Childs C, Stoner HB, Little RA. Cutaneous heat loss shortly after burn injury in children. Clin Sci 1992; 83: 117-26.

4 Childs C. Metabolic rate at rest and during sleep in a thermoneutral environment. Arch Dis Child 1993; 68: 658-61.

5 Muir IFK, Barclay TL. Burns and their treatment. London: Lloyd-Luke, 1962.

6 Wailoo MP, Petersen SA, Whittaker H, Goodenough P. The thermal environment in which 3-4 month old infants sleep at home. Arch Dis Child 1989; 64: 600-4.

7 McGuinness K, Childs C. Development of an indirect calorimeter for use in infants and children. Clin Phys Physiol Meas 1991; 12: 343-51.

8 Childs C, Stoner HB, Little RA, Davenport PJ. A comparison of some thermoregulatory responses in healthy children and in children with burn injury. Clin Sci 1989; 77; 425-9.

9 Childs C, Stoner HB, Little RA. Evidence for a central inhibition of heat loss during the acute phase of burn injury in children. Arch Emerg Med 1990; 7: 303-4.

10 Cooper AL, Horan MA, Little RA, Rothwell NJ. Metabolic and febrile responses to typhoid vaccine in humans and febrile responses to typhoid vaccine in humans 2322-8.

11 Large J, Childs C. The effect of feeding on metabolic rate in the febrile burned child. Proceedings of the 5th European Burns Association. Brighton Congress, 1993.

12 Clark RP, Edholm OG. Man and his thermal environment. London: Edward Arnold, 1985.

13 Little RA, Stoner HB, Frayn KN. Substrate oxidation shortly after accidental injury. Clin Sci 1981; 61: 789-91.

14 Childs C, Ratcliffe RJ, Holt I, Hopkins SJ, Little RA. The relationship between interleukin-1, interleukin-6 and pyrexia in burned children. In: Dinarello CA, Kluger M, Powanda M, Oppenheim J, eds. Physiological and Powanda M, Oppenheim J, eds. Physiological and pathophysiological effects of cytokines - Progress in leucocy
biology. New York: Wiley-Liss, 1990: 10b: 295-300.

15 Deitch EA. Intestinal permeability is increased in burn patients shortly after injury. Surgery 1990; 107: 411-6.

16 Childs C, Watson SB, Fisher MI, Ward ID, Davenport PJ, Little RA. Gut permeability in the acutely burned child. Proceedings of the Association of Clinical Biochemists 1992; June: 52.

17 Rothwell NJ. Autonomic and central control of thermogenesis. In: Rothwell NJ, Stock MJ, eds. Obesity and cachexia - physiological mechanisms and new approaches to pharmacological control. Chichester: John Wiley, 1991.

18 Childs C, Little RA. Paracetamol (acetaminophen) in the

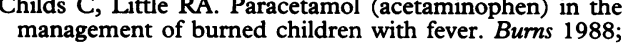
14: 343-8.

19 Morimoto A, Murakami N, Nakamori T, Watanabe T. Multiple control of fever production in the central nervous system of rabbits. $\mathcal{F}$ Physiol 1988; 397: 269-80.

20 Childs C, Hall T, Little RA, Davenport PJ. Dietary intake and changes in body weight in burned children. Burns 1990; 16: 418-22. 